\title{
Stage IIIB Cutaneous Melanoma AJCC v7
}

National Cancer Institute

\section{Source}

National Cancer Institute. Stage IIIB Cutaneous Melanoma A/CC V7. NCI Thesaurus.

Code C86051.

Stage IIIB includes: (T1-4b, N1a, M0); (T1-4b, N2a, M0); (T1-4a, N1b, M0); (T1-4a, N2b, M0); (T1-4a, N2c, M0). T1-4b: Ulcerated cutaneous melanoma of any thickness. T1-4a: Non-ulcerated cutaneous melanoma of any thickness. N1a: Cutaneous melanoma with micrometastasis in one regional lymph node. N2a: Cutaneous melanoma with micrometastases in 2-3 regional lymph nodes. N1b: Cutaneous melanoma with macrometastasis in one regional lymph node. N2b: Cutaneous melanoma with macrometastases in 2-3 regional lymph nodes. N2c: Cutaneous melanoma with intralymphatic metastases (in transit or satellite metastases) without metastatic nodes. M0: No detectable evidence of distant metastases. (from AJCC 7th Ed.) 